\title{
Efficacy and Safety of Psychomotor Approach in Children Affected by Selective Mutism: A Multicenter Study in Italian Pediatric Population
}

Maria Esposito $^{1^{*}}$, Francesco Precenzano ${ }^{1}$, Maria Ruberto ${ }^{2}$, Marco Carotenuto $^{1}$

${ }^{1}$ Clinic of Child and Adolescent Neuropsychiatry, Department of Mental Health, Physical and Preventive Medicine, Second University of Naples, Naples, Italy

${ }^{2}$ Department of Odonto-Stomathologic Disciplines, Pathology - Orthopedic Sciences, Second University of Naples, Naples, Italy

Abstract $\quad$ Publication History:

Introduction: Selective mutism is a relative rare disease in children coded by DSM-V in anxiety disorders. No specific treatment were yet coded, although the disabling nature of the disease.

Received: January 18, 2015

Aims of the present study were to verify the effect of the six months standard psychomotor approach on a population of children affected by selective mutism and the effects on life aspects.

Materials and Methods: The study population was composed of 67 children (39 males, mean age of 7.93 \pm 1.05 years) recruited in the Child and Adolescent Neuropsychiatric Center of Second University of Naples. The psychomotor approach was administered by trained child therapists in residential settings three per week, with the same therapist for each child; all therapists shared the same protocol. The standard psychomotor session length was 45 minutes. At T0 and after 6 months (T1) of treatments, the patients underwent a behavioural and SM severity assessment. In order to verify the effects of the Accepted: July 04, 2015

Published: July 06, 2015

\section{Keywords:}

Psychomotor approach, Psychomotricity, Pediatric selective mutism psychomotor approach, the CBCL and SMQ were administered to parents of all children.

Results: After 6 months of psychomotor treatment SM children showed a significant reduction in Social Relations, Anxious/Depressed, Social problems and Total problems $(\mathrm{p}<0.001)$, Withdrawn $(\mathrm{p}=0.007)$ and Internalizing problems $(\mathrm{p}=0.020)$ among $\mathrm{CBCL}$ scores. (Table 1)

Regarding SM severity according SMQ assessment, our sample showed a reduction of SM symptoms in all situations (School, $\mathrm{p}=0.003$; Family, $\mathrm{p}=0.018$; and Social, $\mathrm{p}=0.030$ situations) and in SMQ total score $(\mathrm{p}<0.001)$.

Conclusion: Our preliminary results may suggest the posiᄀtive effect of the psychomotor approach in rehabilitative program for children affected by selective mutism, even if further researches are needed.

\section{Introduction}

As reported by DSM-5 [1], the Selective mutism (SM) may be considered as a relatively rare childhood developmental disorder characterized by the permanent failure to speak in specific social situations, despite correct language competence in other ones, with a worldwide prevalence rates ranging from $0.2 \%$ to $2 \%$ among elementary school children [2-5]. SM has been reported as accompanied by relevant impairments in academic, social, familial and personal functioning as expression of social phobia $[1,6]$. Moreover, retrospective studies seem to indicate the early onset of the disease [7], more common in girls, [8] and in general identified as predictive for adult internalizing disorders [7].

SM is probably under-diagnosed [9] with a prevalence probably greater than usually recognized [3]. The onset is generally slow and insidious, $[10,11]$ with decreasing with age, $[12]$ and good remission rates have recently been reported in young adulthood, as reported by Steinhausen in 2006 [11].On the other hand, the impaired speech is not caused by problems in language comprehension or expression [13, 14].

Moreover, despite the disabling nature of SM with an important negative impact on all life aspects both short- and long-term functioning in pediatric age, the evidence for effective treatments is scarce and limited to isolated case-series [15-19]. Presently, a comprehensive and uniform theory about the etiology, assessment, and treatment of SM does not yet exist [20].

Conversely, treatment options include individual behavioral therapy, family therapy, psychotherapy and pharmacological therapy with antidepressants and/or anxiolytic drugs [20].
On the other hand, as showed by Carbone et al. the social skills training may merit inclusion in the intervention options for children with anxiety disorders as well as children with SM [21].

In fact, about the treatment proposal, the recent literature suggests the positive effects of the 24 weeks of specific Integrated Behavior Therapy for Selective Mutism (IBTSM) program with high rate of treatment responders $(75 \%)$ and significant improvements in number of words spoken at school compared to baseline [22-24].

Clinical literature reviews indicate that among psychosocial treatments, initial reports emphasize the use of psychodynamic psychotherapeutic models, [25] followed by cognitive and behavioural methods [26,27]. More recent reports have been advocated the benefits of psychopharmacological treatments in children with SM [28-30].

In general, the treatment for the most cases of SM is delayed for several years, however, because these children are simply considered shy by parents or because the children often speak well at "Corresponding Author: Dr. Maria Esposito, Clinic of Child and Adolescent Neuropsychiatry, Department of Mental Health, Physical and Preventive Medicine, Second University of Naples, Via Sergio Pansini 580131 Napoli, Italy; Tel: + 39081 5666988;Fax: +39 081 5666694; E-mail: maria.esposito2@unina2.it

Citation: Esposito M, Precenzano F, Ruberto M, Carotenuto M (2015) Efficacy and Safety of Psychomotor Approach in Children Affected by Selective Mutism: a Multicenter Study in Italian Pediatric Population. Int J Psychol Behav Anal 1: 107. doi: http://dx.doi.org/10.15344/2455-3867/2015/107

Copyright: (c) 2015 Esposito et al. This is an open-access article distributed under the terms of the Creative Commons Attribution License, which permits unrestricted use, distribution, and reproduction in any medium, provided the original author and source are credited. 
Citation: Esposito M, Precenzano F, Ruberto M, Carotenuto M (2015) Efficacy and Safety of Psychomotor Approach in Children Affected by Selective Mutism: a Multicenter Study in Italian Pediatric Population. Int J Psychol Behav Anal 1: 107. doi: http://dx.doi.org/10.15344/2455-3867/2015/107

Page 2 of 5

home, [31,32] but while the disorder progresses, children may experience different disabling problems such as peer rejection, few friendships, incomplete verbal academic tasks, or inadequate language or social skills [33].

In 2007 Sharp et al. have been discussed the etiology of SM, emphasizing it as better included among anxiety-related disorder [32].

Moreover, as remarked by Ford et al. [34], the SM has been linked with a slow-to-warm and shy temperament, suggesting that behavioral inhibition may represent a precursor to onset of the condition [34]. In this framework, the psychomotor approach used for many other disorders in pediatric age, could be considered as promising behavioural therapy for SM children. In fact, the psychomotor approach may tend: 1) to help the child and his parents to put their attention in an appropriate manner within the relationship rather than the outside, in particular by helping them to recognize and manage those situations in which illuminate the anxious mechanisms that maintain the SM;2) to restore communication and empathic sharing between child and other subjects different from mother or parents; 3 ) to introduce a greater capacity for recognition and regulation of internal emotional conditions in order to be able to manage them.

To the best our knowledge, there are no specific studies about the feasibility and effectiveness of psychomotor approach for children affected by SM. Therefore, the aims of the present study were to verify the effect of the six months standard psychomotor approach on a population of children affected by selective mutism and the effects on life aspects.

\section{Materials and Methods}

The study population was composed of 67 children ( 39 males, mean age of $7.93 \pm 1.05$ years) affecting by SM referred between January 2009 to March 2013: to the Child and Adolescent Neuropsychiatry Clinic at the Second University of Naples.

Exclusion criteria were: neurological or psychiatric symptoms, language and/or learning disorders, behavioural problems and/or mental retar $\neg$ dation (intelligence quotient $[\mathrm{IQ}] \leq 70$ ).

As reported in a previous work, [35] after the baseline (T0) evaluations all subjects underwent a psychomotor approach therapy program for 6 months [35] that was administered by trained child therapists in residential settings three per week, with the same therapist for each child; all therapists shared the same protocol [35]. The standard psychomotor session length was 45 minutes [35].

At baseline and after psychomotor approach therapy program (T1), the SM children underwent a behavioural and SM severity assessment.

All parents gave written informed consent during the first screening visit.

The reported investigation has been carried out in accor $\neg$ dance with the principles of the Declaration of Helsinki [36].

The Departmental Ethics Committee of the Second University of Naples approved the study.

\section{Behavioral assessment}

As previously reported by Esposito et al. in 2013,35,37 to assess the psychological and social competence of children, the Italian version of the Child Behavior Checklist questionnaire (CBCL) has been used [38].
The parents of children aged 6-18 years filled out the CBCL questionnaire referring to the previous period of 6 months. The eight factors provided (withdrawn, somatic complaints, anxious/depressed, social problems, thought problems, attention-hyperactive, rulebreaking behaviour, and aggressive behaviour) and three global scores for externalizing, internalizing behaviors and a total behavior score were computed in order to obtain the children behavioural profiles.

\section{Selective mutism severity assessment}

In order to evaluate the degree of a child's speech inhibition in various situations the Selective Mutism Questionnaire (SMQ) by Bergman39 was applied. The SMQ was composed by 17 questions regarding situations in which children are expected to speak (e.g., "When called on by his/her teacher, my child would answer") spanning three domains: "at school" (five items), "with family" (five items), and "in social situations" (seven items) [40]. Three overall interference and distress questions supplement the situational statements (e.g., "Overall, how much did not talking interfere with daily living for your child?") [40]. The frequency of each item was rated, using a 4 -point scale (1=Always; $2=$ Often; $3=$ Seldom; and $4=$ Never for speaking situations) and the interference/distress items were scored in an independent scale ( $1=$ Not at all, $2=$ Slightly, $3=$ Moderately, $4=$ Extremely) [40].

The global scores range from 17-68, with higher scores representing greater SM severity (i.e., not talking behaviors) and SM-related impairment [40].

The SMQ is the sole specific validated tool to assess the severity of the $\mathrm{SM}$ in pediatric age.

\section{Statistical analysis}

In order to compare the all examined variables, ANOVA analysis was applied. p-values $<0.05$ were considered statistically significant.

All data were coded and analyzed using the commercially available STATISTICA 6.0 package for Windows (StatSoft, Inc, Tulsa, OK, USA).

\section{Results}

After 6 months of psychomotor treatment SM children showed a significant reduction in Social Relations, Anxious/Depressed, Social problems and Total problems $(\mathrm{p}<0.001)$, Withdrawn $(\mathrm{p}=0.007)$ and Internalizing problems $(\mathrm{p}=0.020)$ among CBCL scores (Table 1$)$.

Regarding SM severity according SMQ assessment, our sample showed a reduction of SM symptoms in all situations (School, $\mathrm{p}=0.003$; Family, $\mathrm{p}=0.018$; and Social, $\mathrm{p}=0.030$ situations) and in SMQ total score $(\mathrm{p}<0.001)$. (Table 2$)$.

\section{Discussion}

The main finding of the present research could be summarized in education in SM symptoms and in the behavioral improvement after the psychomotor approach for 6 months.

In this perspective, considering the brevity of the treatment, the positive effects must be considered exclusively related to psychomotor therapy and not linked to developmental maturational phenomena or other factors occurred. 
Citation: Esposito M, Precenzano F, Ruberto M, Carotenuto M (2015) Efficacy and Safety of Psychomotor Approach in Children Affected by Selective Mutism: a Multicenter Study in Italian Pediatric Population. Int J Psychol Behav Anal 1: 107. doi: http://dx.doi.org/10.15344/2455-3867/2015/107

Page 3 of 5

\begin{tabular}{|c|c|c|c|}
\hline & $\begin{array}{l}\text { SM at T0 } \\
N=67\end{array}$ & $\begin{array}{l}\mathrm{SM} \text { at } \mathrm{T} 1 \\
\mathrm{~N}=67\end{array}$ & $\mathbf{p}$ \\
\hline Activities competence & $35.48 \pm 8.19$ & $34.12 \pm 7.01$ & 0.304 \\
\hline Social Relations & $68.59 \pm 5.46$ & $58.12 \pm 6.90$ & $<0.001$ \\
\hline School competence & $61.03 \pm 5.98$ & $58.96 \pm 6.32$ & 0.054 \\
\hline Competence Total & $34.42 \pm 8.15$ & $35.26 \pm 6.37$ & 0.507 \\
\hline Withdrawn & $63.18 \pm 7.14$ & $59.82 \pm 6.97$ & 0.007 \\
\hline Somatic Complaints & $52.03 \pm 8.15$ & $51.94 \pm 9.03$ & 0.952 \\
\hline Anxious/Depressed & $72.36 \pm 5.66$ & $68.94 \pm 6.06$ & $<0.001$ \\
\hline Social problems & $59.07 \pm 8.33$ & $52.98 \pm 9.67$ & $<0.001$ \\
\hline Thought problems & $47.81 \pm 9.04$ & $45.52 \pm 9.73$ & 0.160 \\
\hline Attention-hyperactive & $36.48 \pm 9.61$ & $38.93 \pm 10.15$ & 0.154 \\
\hline Delinquent & $34.59 \pm 6.76$ & $36.19 \pm 7.83$ & 0.208 \\
\hline Aggressive & $41.35 \pm 9.72$ & $44.05 \pm 8.77$ & 0.094 \\
\hline Internalizing problems & $70.82 \pm 6.51$ & $68.04 \pm 7.19$ & 0.020 \\
\hline Externalizing problems & $49.34 \pm 11.09$ & $48.01 \pm 10.83$ & 0.484 \\
\hline Total problems & $72.03 \pm 9.14$ & $63.24 \pm 8.51$ & $<0.001$ \\
\hline
\end{tabular}

Table 1: Description of the Child Behavior Checklist scale scores among children affected by selective mutism at T0 and after six months of psychomotor therapy $(\mathrm{T} 1)$.

Table 1 shows the differences (mean and SD) of SM children in CBCL items between baseline (T0) and after 6 months of psychomotor treatment (T1).

The Chi-square test was used.

p values $<0.05$ were considered statistically significant

\begin{tabular}{|l|l|l|l|}
\hline & $\begin{array}{l}\text { SM at T0 } \\
\text { N=67 }\end{array}$ & $\begin{array}{l}\text { SM at T1 } \\
\text { N=67 }\end{array}$ & p \\
\hline SMQ School & $20.11 \pm 6.47$ & $16.94 \pm 5.83$ & 0.003 \\
\hline SMQ Family & $12.05 \pm 5.83$ & $10.03 \pm 3.72$ & 0.018 \\
\hline SMQ Social Situations & $28.24 \pm 4.19$ & $26.87 \pm 2.92$ & 0.030 \\
\hline SMQ Total score & $61.03 \pm 9.57$ & $52.76 \pm 8.79$ & $<0.001$ \\
\hline
\end{tabular}

Table 2: Description of the Selective Mutism Questionnaire (SMQ) values at T0 and after six months of psychomotor treatment (T1).

Table 2 shows comparison of SM severity according to Selective Mutism Questionnaire (SMQ) between baseline (T0) and after 6 months of psychomotor treatment (T1) in SM children.

The Chi-square test was used.

$\mathrm{p}$ values $<0.05$ were considered statistically significant.

In general, SM may be considered as still poorly understood condition, and debate continues regarding etiology and classification [32]. Moreover, as highlighted in DSM-51, the psychodynamic factors, family dysfunction, neurodevelopmental problems, childhood social phobia and oppositional behavior may be proposed as etiological factors [1].

In this framework, our results about the efficacy of a psychomotor approach on the behavioural characteristics of SM children could be interpreted as the reason of the reduction in SM severity after 6 months of psychomotor treatment $(\mathrm{p}<0.001)$.

On the other hand, yet in 1995 Black et al. has reported that anxiety during childhood could be masked as shyness, timidity and/or social withdrawal as often reported by parents of children suffering by SM. In fact, about $70 \%$ of the first degree family members of SM children report social anxiety, and about $37 \%$ report selective mutism [41]. Moreover, also delayed speech, articulation speech problems and other communication disorders were described in about $30 \%-70 \%$ of SM cases [42-44].
Conversely, about the behavioural therapies potentially useful for SM, the psychomotor approach may be considered as really promising because the more general effects of improving in postural tone, mobility, anxiety and self-confidence [45].

In another light, some reports have been identified the SM as an oppositional and manipulative withholding of speech, [46] although the findings in clinical literature seem to be contradictory.

In fact, since 1996 Steinhausen and Juzi8 have been reported that approximately one-fifth of a mixed clinical and nonclinical SM population demonstrated oppositional defiant and aggressive behavior [47]. Additionally, children with concurrent SM and social phobia seem to present higher delinquent behavior scores and nearly six times more oppositional defiant disorder diagnosis than children affected by social phobia, [48] while other studies have been found no differences in the ratings of externalizing and oppositional behavior between children with SM and typically developing peers [2,33,47-50]. In this light, our results seem to confirm these data demonstrating low level of externalizing symptoms both at baseline that after 6 months of psychomotor treatment. 
Citation: Esposito M, Precenzano F, Ruberto M, Carotenuto M (2015) Efficacy and Safety of Psychomotor Approach in Children Affected by Selective Mutism: a Multicenter Study in Italian Pediatric Population. Int J Psychol Behav Anal 1: 107. doi: http://dx.doi.org/10.15344/2455-3867/2015/107

Page 4 of 5

Conversely, SM and anxiety disorders are closely related suggesting that SM is seen as a persistent childhood disorder that results in high levels of anxiety, and is also seen as the most extreme form of childhood social phobia $[1,41,42]$.

Although there is no coded gold standard for SM treatment, we could assume that treating anxiety in order to improve speech could appears to be an aetiologically suggestive therapeutic option, [51,52] although the evidence of the pharmacological effect some drugs is undeniable $[53,54]$. Unfortunately, in pediatric age the pharmacotherapy cannot be recommended as the first choice of treatment and the nonpharmachological approachs could be considered more suitable and more accepted by parents.

Conversely, as reported in many other articles, [55-57] the importance of playing in pediatric age is ascertained for the whole development, including behavioral control, and rules acquisition [47,58-60].

In this light, our results have been highlighted the importance of a naturalistic, child-tailored approach for SM in pediatric age. On the other hand we have to take into account some limitations for the present study such as the small sample size of children, and such the lack of longitudinal evaluation of long-term results.

In conclusion, our preliminary results may suggest the positive effect of the psychomotor approach in rehabilitative program for children affected by selective mutism, even if further researches are needed.

\section{Competing Interests}

The author declare that he has no competing interests.

\section{Author Contributions}

All the authors substantially contributed to the study conception and design as well as the acquisition and interpretation of the data and drafting the manuscript.

\section{References}

1. American Psychiatric Association: Diagnostic and Statistical Manual of Mental Disorders, Fifth Edition. Arlington, VA, American Psychiatric Association, 2013

2. Bergman RL, Keller M, Wood J, Piacentini J, Mc Cracken J Selective Mutism Questionaire (SMQ): development and findings. Poster session presented at the American Academy of Child and Adolescent Psychiatry, 2001, Honolulu.

3. Bergman RL, Piacentini J, McCracken JT (2002) Prevalence and description of selective mutism in a school-based sample. J Am Acad Child Adolesc Psychiatry 41: 938-946.

4. Kopp S, Gillberg C (1997) Selective mutism: a population-based study: a research note. J Child Psychol Psychiatry 38: 257-262.

5. Manassis K (2009) Silent suffering: understanding and treating children with selective mutism. Expert Rev Neurother 9: 235-243.

6. Black B, Uhde TW (1992) Elective mutism as a variant of social phobia. J Am Acad Child Adolesc Psychiatry 31: 1090-1094.

7. Wright $\mathrm{HH}$, Miller MD, Cook MA, Littmann JR (1985) Early identification and intervention with children who refuse to speak. J Am Acad Child Psychiatry 24: $739-746$

8. Steinhausen HC, Juzi C (1996) Elective mutism: an analysis of 100 cases. J Am Acad Child Adolesc Psychiatry 35: 606-614.
9. Hesselman S (1983) Elective mutism in children 1877-1981. A literary summary. Acta Paedopsychiatr 49: 297-310.

10. Kolvin I, Fundudis T (1981) Elective mute children: psychological development and background factors. J Child Psychol Psychiatry 22: 219232.

11. Steinhausen HC, Wachter M, Laimböck K, Metzke CW (2006) A long-term outcome study of selective mutism in childhood. J Child Psychol Psychiatry 47: 751-756

12. Hooper SR, Linz TD (1992) Elective mutism. In Hooper SR, Hynd GW, \& Mattison RE (Eds.), Child psychopathology: Diagnostic, criteria and clinical assessment, Hillsdale, NJ: Lawrence Erlbaum, (pp. 409-459).

13. Karakaya I, SiÅŸmanlar SG, OÃß OY, Memik NC, CoÅŸkun A, et al. (2008) Selective mutism. A school-based cross-sectional study from Turkey. Eur Child Adolesc Psychiatry 17: 114-117.

14. Kumpulainen K, Räsänen E, Raaska H, Somppi V (1998) Selective mutism among second-graders in elementary school. Eur Child Adolesc Psychiatry 7: 24-29.

15. SelimoÄ Ÿlu M, AkdaÄ $\ddot{Y}$ R, Kirpinar I (1995) A case of childhood shigellosis with mutism. Turk J Pediatr 37: 431-434.

16. Jacobsen T (1995) Case study: is selective mutism a manifestation of dissociative identity disorder? J Am Acad Child Adolesc Psychiatry 34: 863866.

17. Elamin A (1991) Goitre and deaf-mutism. Ups J Med Sci 96: 213-218.

18. Louden DM (1987) Elective mutism: a case study of a disorder of childhood. J Natl Med Assoc 79: 1043-1048.

19. Eldar S, Bleich A, Apter A, Tyano S (1985) Elective mutism--an atypical antecedent of schizophrenia. J Adolesc 8: 289-292.

20. Wong $P(2010)$ Selective mutism: a review of etiology, comorbidities, and treatment. Psychiatry (Edgmont) 7: 23-31.

21. Carbone D, Schmidt LA, Cunningham CC, McHolm AE, Edison S, et al. (2010) Behavioral and socio-emotional functioning in children with selective mutism: a comparison with anxious and typically developing children across multiple informants. J Abnorm Child Psychol 38: 1057-1067.

22. Bergman RL, Gonzalez A, Piacentini J, Keller ML (2013) Integrated Behavior Therapy for Selective Mutism: a randomized controlled pilot study. Behav Res Ther 51: 680-689.

23. James AC, James G, Cowdrey FA, Soler A, Choke A (2013) Cognitive behavioural therapy for anxiety disorders in children and adolescents. Cochrane Database Syst Rev 6:CD004690.

24. Reuther ET, Davis TE 3rd, Moree BN, Matson JL (2011) Treating selective mutism using modular CBT for child anxiety: a case study. J Clin Child Adolesc Psychol 40: 156-163.

25. Wergeland H (1979) Elective mutism. Acta Psychiatr Scand 59: 218-228.

26. Fung DS, Manassis K, Kenny A, Fiksenbaum L (2002) Web-based CBT for selective mutism. J Am Acad Child Adolesc Psychiatry 41: 112-113.

27. Marcus A, Müller F, Rothenberger A, Schmidt MH (1993) Total mutism--a case report of a rare psychiatric disorder and approaches for behaviour therapy. Acta Paedopsychiatr 56: 41-46.

28. Carlson JS, Kratochwill TR, Johnston HF (1999) Sertraline treatment of 5 children diagnosed with selective mutism: a single-case research trial. $\mathrm{J}$ Child Adolesc Psychopharmacol 9: 293-306.

29. Dummit ES, Klein RG, Tancer NK, Asche B, Martin J (1996) Fluoxetine treatment of children with selective mutism: an open trial. J Am Acad Child Adolesc Psychiatry 35: 615-621.

30. Sharkey L, Mc Nicholas F, Barry E, Begley M, Ahern S (2008) Group therapy for selective mutism - a parents' and children's treatment group. $J$ Behav Ther Exp Psychiatry 39: 538-545.

31. Andersson CB, Thomsen PH (1998). Electively mute children: An analysis of 37 Danish cases. Nord Journal of Psychiatry 52: 231-238.

32. Sharp WG, Sherman C, Gross AM (2007) Selective mutism and anxiety: a review of the current conceptualization of the disorder. J Anxiety Disord 21: 568-579. 
Citation: Esposito M, Precenzano F, Ruberto M, Carotenuto M (2015) Efficacy and Safety of Psychomotor Approach in Children Affected by Selective Mutism: a Multicenter Study in Italian Pediatric Population. Int J Psychol Behav Anal 1: 107. doi: http://dx.doi.org/10.15344/2455-3867/2015/107

33. Cunningham CE, McHolm AE, Boyle MH (2006) Social phobia, anxiety, oppositional behavior, social skills, and self-concept in children with specific selective mutism, generalized selective mutism, and community controls. Eur Child Adolesc Psychiatry 15: 245-255.

34. Ford MA, Sladesczek IE, Carlson J, Krochwell TR (1998) Selective mutism Phenomenological characteristics. School Psychology Quarterly 13: 192 227.

35. Esposito M, Gimigliano F, Ruberto M, Marotta R, Gallai B, et al. (2013) Psychomotor approach in children affected by nonretentive fecal soiling (FNRFS): a new rehabilitative purpose. Neuropsychiatr Dis Treat 9: 14331441.

36. World Medical Association (2008) World Medical Association Declaration of Helsinki: Ethical Principles for Medical Research Involving Human Subjects.

37. Carotenuto M, Esposito M, Di Pasquale F, De Stefano S, Santamaria F (2013) Psychological, cognitive and maternal stress assessment in children with primary ciliary dyskinesia. World J Pediatr 9: 312-317.

38. Achenbach TM (1991) Manual for the Child Behavior Checklist/4-18 and 1991 Profile. University of Vermont Department of Psychiatry, Burlington, VT.

39. Bergman RL, Keller ML, Piacentini J, Bergman AJ (2008) The development and psychometric properties of the selective mutism questionnaire. J Clin Child Adolesc Psychol 37: 456-464.

40. Letamendi AM, Chavira DA, Hitchcock CA, Roesch SC, Shipon-Blum E, et al. (2008) Selective Mutism Questionnaire: measurement structure and validity. J Am Acad Child Adolesc Psychiatry 47: 1197-1204.

41. Black B, Unde TW (1995) Psychiatric characteristics of children with selective mutism: a pilot study. J Am Acad Child Adolesc Psychiatry 34 847-856

42. Kristensen $H(2000)$ Selective mutism and comorbidity with developmental disorder/delay, anxiety disorder, and elimination disorder. J Am Acad Child Adolesc Psychiatry 39: 249-256.

43. Kristensen $\mathrm{H}$ (2001) Multiple informants' report of emotional and behavioural problems in a nation-wide sample of selective mute children and controls. Eur Child Adolesc Psychiatry 10: 135-142.

44. Kristensen $\mathrm{H}$, Torgersen $\mathrm{S}$ (2001) MCMI-II personality traits and symptom traits in parents of children with selective mutism: a case-control study. $J$ Abnorm Psychol 110: 648-652.

45. Aumignon M, Kreutz G, Beauchet K, Gindre D (2002) [Contribution of psychomotricity in respiratory rehabilitation programs]. Rev Mal Respir 19: 45-51.

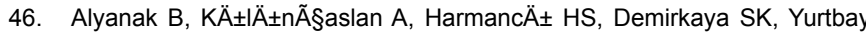
T, et al. (2013) Parental adjustment, parenting attitudes and emotional and behavioral problems in children with selective mutism. J Anxiety Disord 27: $9-15$.

47. Krohn DD, Weckstein SM, Wright HL (1992) A study of the effectiveness of a specific treatment for elective mutism. J Am Acad Child Adolesc Psychiatry 31: 711-718.

48. Yeganeh R, Beidel DC, Turner SM, Pina AA, Silverman WK (2003) Clinical distinctions between selective mutism and social phobia: an investigation of childhood psychopathology. J Am Acad Child Adolesc Psychiatry 42: 1069-1075.

49. Cunningham CE, McHolm A, Boyle MH, Patel S (2004) Behavioral and emotional adjustment, family functioning, academic performance, and social relationships in children with selective mutism. J Child Psycho Psychiatry 45: 1363-1372.

50. Vecchio JL, Kearney CA (2005) Selective mutism in children: comparison to youths with and without anxiety disorders. Journal of Psychopathology and Behavioral Assessment 27: 31-37.

51. Manassis K, Mendlowitz S, Menna R (1997) Child and parent reports of childhood anxiety: differences in coping styles. Depress Anxiety 6: 62-69.

52. Mclnnes A, Manassis K (2005) When silence is not golden: an integrated approach to selective mutism. Semin Speech Lang 26: 201-210.

53. Black B, Uhde TW (1994) Treatment of elective mutism with fluoxetine: double-blind, placebo-controlled study. J Am Acad Child Adolesc Psychiatry 33: $1000-1006$.

Int J Psychol Behav Anal

ISSN: 2455-3867
54. Dummit ES, Klein RG, Tancer NK, Asche B, Martin J, et al. (1997) Systematic assessment of 50 children with selective mutism. J Am Acad Child Adolesc Psychiatry 36: 653-660.

55. Baron-Cohen S (1987) Autism and symbolic play. British Journal of Developmental Psychology 5: 139-148.

56. Stagnitti K (2009) Play intervention-The Learn to Play Program. In K. Stagnitti \& R. Cooper (Eds.), Play as therapy: Assessment and therapeutic interventions, London: Jessica Kingsley Publishers, (pp. 176-186).

57. Vygotsky, L. Play and its role in the mental development of a child. In J. Bruner, A. Jolly, \& K. Sylva (Eds.), Play, its role in development and evolution 1976 (pp. 537-554). Harmondsworth, Middlesex: Penguin.

58. Latour AM (1994) [Psychosis and psychomotricity]. Soins Psychiatr : 2024,27

59. Rivière J (1993) [Space perception and psychomotricity in infants with motor deficiency]. Pediatrie 48: 757-758.

60. Bergeron M (1950) [Motor development and psychomotricity in the child and the adolescent]. Sem Hop 26: 4339-4344. 